IJBPAS, December, 2021, 10(12): 4727-4729

ISSN: $2277-4998$

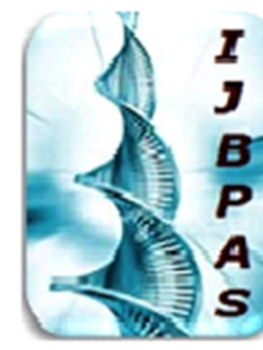

International Journal of Biology, Pharmacy and Allied Sciences (IJBPAS)

'A Bridge Betuben Caboratory and QRendo'

WwW.ijbpas.com

\title{
CASE REPORT ON DERMATOFIBROSARCOMA
}

\section{ANAND.J ${ }^{1 *}$, KARTHIKEYAN $^{2}$ AND CHITRA $^{3}$}

1: Junior Resident, Department of General Surgery, Sree Balaji Medical College and Hospital,

Bharath University Chrompet, Chennai, India

2: Assistant Professor, Department of General Surgery, Sree Balaji Medical College and Hospital, Bharath University Chrompet, Chennai, India.

3: Professor, Department of General Surgery, Sree Balaji Medical College and Hospital, Bharath University Chrompet, Chennai, India

*Corresponding Author: Dr. Anand J: E Mail: ajanand003@gmail.com

Received 28 ${ }^{\text {th }}$ March 2021; Revised 28 ${ }^{\text {th }}$ April 2021; Accepted 25 ${ }^{\text {th }}$ May 2021; Available online $1^{\text {st }}$ Dec. 2021

https://doi.org/10.31032/IJBPAS/2021/10.12.58001

ABSTRACT

Dermatofibrosarcoma is a slow growing, uncommon, dermal soft tissue neoplasm. It occurs more commonly over back- trunk followed by abdominal wall, head, neck and proximal extremities, but rarely in toes [1]. It has high recurrence rate but low metastasic capacity.

\section{Keywords: Dermatofibrosarcoma, metastasic capacity, swelling}

\section{CASEREPORT}

A 52 year old male presented to the OPD with complaints of mass in his head for past 2.5 year. Swelling was gradually progressive in nature, not associated with pain,no history of fever.Patient is a known case of hypertensive for past 10 years and is on treatment.L/E:A swelling of $6 \times 5 \mathrm{cms}$ was present in his occipital region. The swelling was nodular, firm in consistency, mobile with well-defined margins. No warmth, no tenderness (Figure 1).

All laboratory investigations were within normal limits. CT scan showed no intracranial extension. Patient was planned for wide local excision and biopsy (Figure 2). 
Biopsy was taken and sent for HPE Immunostaining for CD 34 turned out to be examination. HPE revealed spindle shaped positive. Patient was discharged on postcells in the dermis arranged in storiform operative day 14 , the wound was healthy and pattern (Figure 3). healing well.

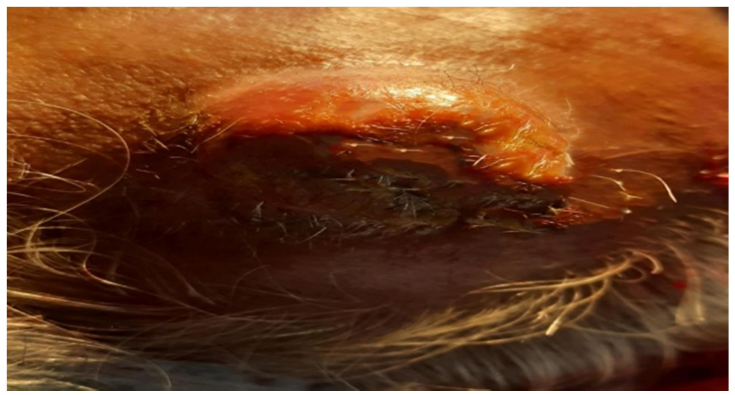

Figure 1

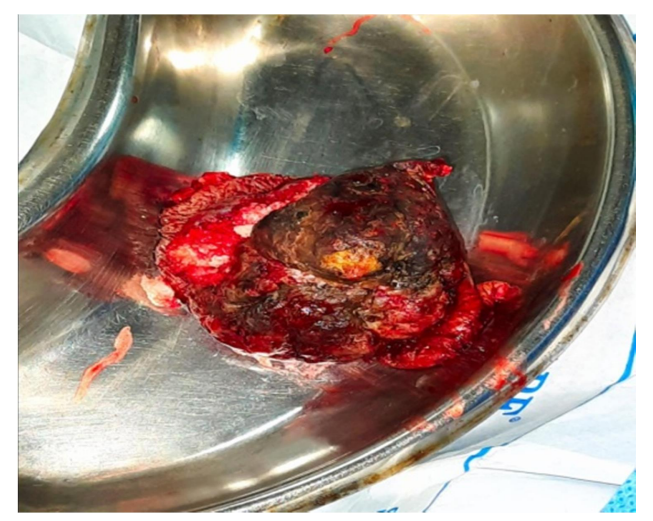

Figure 2

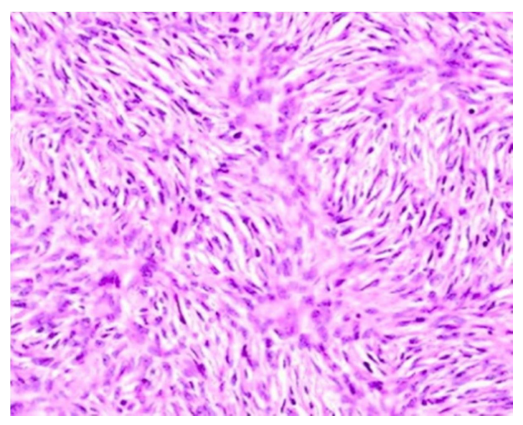

Figure 3

\section{DISCUSSION}

Dermatofibrosarcoma is a rare, cutaneous sarcoma with overexpression of platelet derived growth factor B. It affects man and women equally and the age of presentation is between fourth and seventh decades. It presents as nodular cutaneous mass over trunk, abdominal wall, proximal extremities, 
head and neck. Cytogenetically majority of Dermatofibrosarcoma shows the $\mathrm{t}(17: 12)(\mathrm{q} 22 ; \mathrm{q} 13)$ transformation, which fuses COLIA1 and plate derived growth factor B genes and causes overexpression [2]. It rarely metastasizes. It has good prognosis recurrence is common in 50 to $70 \%$ of cases [3] and can be resected with free margins.

\section{CONCLUSION}

Any painless lump or swellings arising from soft tissues should be carefully evaluated for soft tissue sarcomas, early diagnosis and curative resection has a major role in management of soft tissue sarcoma, thereby improving the prognosis, and even this case was evaluated in such a way and turned out to be Dermatofibrosarcoma which has very good prognosis.Hence it is important to evaluate each swelling in the angle of malignancy so that it can improve the outcome of the disease.

\section{REFERENCES}

[1] Madden C, Spector A, Siddiqui S, Mirkin G, Yim J, Hao X. Dermatofibrosarcoma protuberans on adult toes: a case report and review of the literature. Anticancer research. 2019 Apr 1; 39(4): 2105-11.

[2] Sabiston text book of surgery 20th edition chapter surgical oncology, page number 766 , 5th paragraph.
[3] Swartz's principles of surgery $11^{\text {th }}$ edition, volume1, page number 535, $4^{\text {th }}$ paragraph. 